\title{
Prepartum anaemia: prevention and treatment
}

\author{
Nils Milman
}

Received: 24 April 2008 / Accepted: 26 May 2008 / Published online: 19 July 2008

(C) The Author(s) 2008

\begin{abstract}
This review focuses on the occurrence, prevention and treatment of anaemia during pregnancy in Western societies. Iron deficiency anaemia (IDA) is the most prevalent deficiency disorder and the most frequent form of anaemia in pregnant women. Minor causes of anaemia are folate and vitamin $\mathrm{B}_{12}$ deficiency, haemoglobinopathy and haemolytic anaemia. Anaemia is defined as haemoglobin of $<110 \mathrm{~g} / \mathrm{L}$ in the first and third trimester and $<105 \mathrm{~g} / \mathrm{L}$ in the second trimester. The diagnosis relies on haemoglobin, a full blood count and plasma ferritin, which can be supported by plasma transferrin saturation and serum soluble transferrin receptor. Among fertile, non-pregnant women, $\sim 40 \%$ have ferritin of $\leq 30 \mu \mathrm{g} / \mathrm{L}$, i.e. small or absent iron reserves and therefore an unfavourable iron status with respect to upcoming pregnancy. The prevalence of prepartum anaemia in the third trimester ranges $14-52 \%$ in women taking placebo and 0 $25 \%$ in women taking iron supplements, dependent on the doses of iron. In studies incorporating serum ferritin, the frequency of IDA in placebo-treated women ranges $12-17 \%$ and in iron-supplemented women $0-3 \%$. Requirements for absorbed iron increase during pregnancy from $0.8 \mathrm{mg}$ /day in the first trimester to $7.5 \mathrm{mg}$ /day in the third trimester, on the average $\sim 4.4 \mathrm{mg} / \mathrm{day}$, and dietary measures are inadequate to reduce the frequency of prepartum IDA. However, IDA is efficiently prevented by oral iron supplements in doses of 30 $40 \mathrm{mg}$ ferrous iron taken between meals from early pregnancy
\end{abstract}

\author{
N. Milman \\ Department of Obstetrics and Gynaecology, Gentofte Hospital, \\ University of Copenhagen, \\ Hellerup, \\ Copenhagen, Denmark \\ N. Milman $(\bowtie)$ \\ Lindevangen 87B, \\ 2830 Virum, Denmark \\ e-mail: nils.mil@dadlnet.dk
}

to delivery. Treatment of IDA should aim at replenishing body iron deficits by oral and/or intravenous administration of iron. In women with slight to moderate IDA, i.e. haemoglobin of 90-105 g/L, treatment with oral ferrous iron of $\sim 100 \mathrm{mg} /$ day between meals is the therapeutic option in the first and second trimester; haemoglobin should be checked after 2 weeks and provided an increase of $\geq 10 \mathrm{~g} / \mathrm{L}$, oral iron therapy has proved effective and should continue. Treatment with intravenous iron is superior to oral iron with respect to the haematological response. Intravenous iron is considered safe in the second and third trimester, while there is little experience in the first trimester. Intravenous iron of $600-1,200 \mathrm{mg}$ should be considered: (1) as second option if oral iron fails to increase haemoglobin within 2 weeks; (2) as first option at profound IDA, i.e. haemoglobin of $<90 \mathrm{~g} / \mathrm{L}$ in any trimester beyond 14 weeks gestation; and (3) as first option for IDA in third trimester. Profound IDA has serious consequences for both woman and foetus and requires prompt intervention with intravenous iron. This is especially important for the safety of women who for various reasons oppose blood transfusions.

Keywords Anemia · Iron deficiency · Pregnancy

\section{Introduction}

Iron is an essential micronutrient to man. It is necessary for the synthesis of the haemoglobin in erythrocytes and the myoglobin in myocytes as well as for the function of a wide range of iron-dependent enzymes. An adequate body iron balance is important for our well-being and quality of life [1-3]. In pregnant women, a favourable iron status is a prerequisite for a good course of pregnancy, a normal development of the foetus and maturity of the newborn. There is evidence that iron deficiency, even in the absence of iron deficiency anaemia (IDA), may have a negative 
impact in non-pregnant women, e.g. in relation to decreased cognitive ability and physical performance $[1,2]$. In postpartum women, IDA is associated with emotional instability, depression, stress and lower cognitive performance tests [3]. It is therefore most likely that IDA has the same effect on pregnant women. Furthermore, IDA during pregnancy (prepartum) is associated with premature birth, low birth weight and small for gestational age of the newborn [4-8]. In addition, prepartum IDA predisposes to postpartum IDA [9] and therefore deserves special attention.

We know that iron deficiency and IDA is the most prevalent nutritional deficiency disorder in fertile women on a global scale [10]. There are, however, major differences in iron nutrition between women from developing and developed countries [10]. In developing regions of the world, prepartum IDA is more the rule than the exception with a prevalence of $\sim 52 \%$ [10], whereas in the affluent Western societies the prevalence is far lower due to better nutrition, $\sim 25 \%$ in women not taking iron supplements [ $[10$, $11]$ and $<5 \%$ in women taking $\geq 40 \mathrm{mg}$ ferrous iron daily $[11,12]$. This review shall focus on prevention and treatment of prepartum anaemia in the Western societies.

\section{Assessing iron status}

Iron status can be assessed prepartum by using appropriate markers, predominantly plasma ferritin, plasma transferrin saturation, serum "soluble" transferrin receptor (sTfR) and blood haemoglobin including a full blood count. In healthy subjects, the plasma ferritin concentration is a biomarker for mobilisable body iron reserves, i.e. iron status $[13,14]$. In non-pregnant women, a ferritin concentration of $1 \mu \mathrm{g} / \mathrm{L}$ corresponds to 7-8 $\mathrm{mg}$ of mobilisable iron [13]. In general, ferritin levels of $<30 \mu \mathrm{g} / \mathrm{L}$ indicate a low iron status, i.e. small or no iron reserves as verified by the absence of bone marrow haemosiderin $[14,15]$. Ferritin levels of $<15 \mu \mathrm{g} / \mathrm{L}$ is consistent with iron depletion and ferritin levels of $<12 \mu \mathrm{g} / \mathrm{L}$ are associated with IDA $[15,16]$. In women with inflammatory or infectious disorders, plasma ferritin can be falsely elevated, i.e. out of proportion with body iron reserves. If such conditions are suspected, plasma Creactive protein should be measured as well, in order to assess the degree of inflammation.

Plasma transferrin saturation is calculated from measurement of plasma iron and plasma transferrin. A saturation of $<15 \%$ is considered to indicate an inadequate supply of iron to the erythrons and tissues [16].

The surface of young erythrocytes is crowded with transferrin receptors, which increase in number during iron deficiency [17]. Detached receptors can be measured in serum as soluble receptors (sTfR). In the presence of iron deficiency, serum sTfR rises [17]. Non-pregnant and pregnant women with replete iron stores have similar serum sTfR levels [18]. Serum sTfR can be used to identify women with low plasma ferritin, who in addition have pronounced iron deficiency [18, 19]. The physiologic variations in ferritin may be compensated for by calculating body iron using the sTfR-to-ferritin ratio $[20,21]$. The haemoglobin concentration is still widely used as a marker for iron deficiency. However, haemoglobin is not suitable to assess iron status - especially not in pregnancy where the women display various degrees of haemodilution [22]. In addition, there is a large overlap between the distribution of haemoglobin concentrations in women with and without iron deficiency as shown in Fig. 1 [23].

In short, plasma ferritin provides information about the capacity of body iron reserves, serum sTfR and to some extent plasma transferrin saturation yield information about iron deficiency on the cellular level, whereas haemoglobin gives information about iron deficiency on the functional level. For practical purposes, haemoglobin, i.e. a full blood count, and plasma ferritin are adequate to assess iron status and diagnose IDA in the majority of women.

\section{Iron requirements in pregnancy}

The requirements for absorbed iron increase from $0.8 \mathrm{mg} /$ day in the first trimester to $7.5 \mathrm{mg} /$ day in the third trimester. The average requirement in the entire gestation period is $\sim 4.4$ $\mathrm{mg} /$ day $[9,24]$.

The average total iron requirements in normal pregnancy have been estimated to be $\sim 1,240 \mathrm{mg}[9,24]$. Postpartum, the mother's erythrocyte mass declines to pre-pregnancy levels, and the haemoglobin iron is recycled to body iron reserves. The net iron loss, associated with pregnancy per $\mathrm{se}$, is therefore lower, approximately $630 \mathrm{mg}[9,24]$.

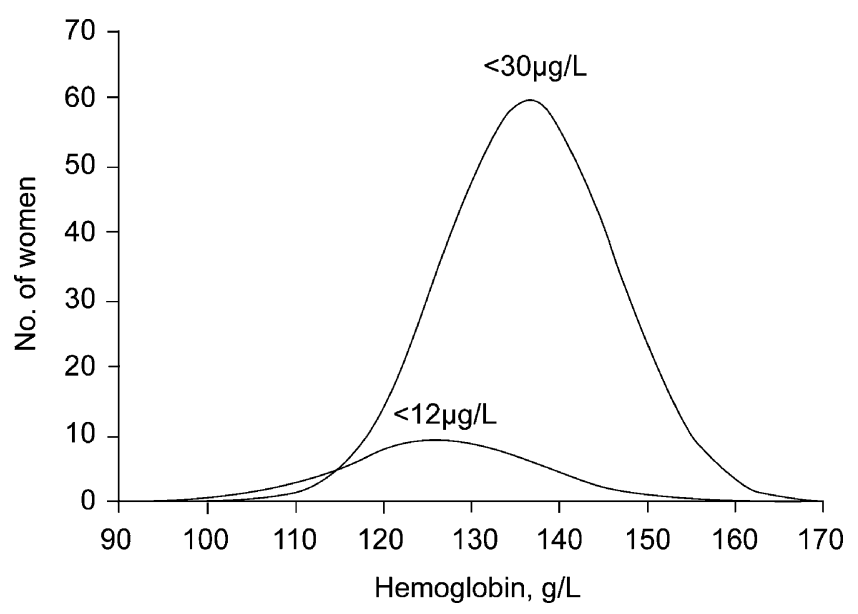

Fig. 1 Distribution of blood haemoglobin concentrations in nonpregnant women with replete iron stores (serum ferritin $>30 \mu \mathrm{g} / \mathrm{L}$ ) and absent iron stores (serum ferritin $<12 \mu \mathrm{g} / \mathrm{L}$ ) [23] 


\section{Fertile women have a low iron status prior to pregnancy}

Scandinavian studies have shown that the majority of menstruating, non-pregnant women have a low iron status with a median plasma ferritin of $38-40 \mu \mathrm{g} / \mathrm{L} ; 10 \%$ of nonblood-donors and $21 \%$ of blood donors have ferritin of $<15$ $\mu \mathrm{g} / \mathrm{L}$, i.e. iron depletion, and $\sim 4 \%$ have IDA. In total, $42 \%$ have ferritin of $\leq 30 \mu \mathrm{g} / \mathrm{L}$, i.e. small or absent iron reserves $[23,25]$. This means that $\sim 40 \%$ of women have an unfavourable pre-pregnancy iron status.

Only $14-20 \%$ have ferritin of $>70 \mu \mathrm{g} / \mathrm{L}$, i.e. iron reserves of $\geq 500 \mathrm{mg}[23,25]$, which almost balances the net iron loss in pregnancy [9, 24]; these women have adequate iron reserves and can carry through pregnancy without developing IDA even though they do not take iron supplements [26].

Certain subgroups of women within the European societies have a higher risk for iron deficiency. These include multipara, multiple pregnancies, blood donors, vegetarians, women of low socio-economic status and immigrants, especially from the Middle and Far East [27].

\section{Defining prepartum anaemia}

The majority of pregnant women in the Western societies presenting with prepartum anaemia have IDA. In a small fraction, other causes of anaemia prevail, mainly folate and/ or vitamin $\mathrm{B}_{12}$ deficiency and inflammatory or infectious diseases. However, recent studies have shown that both plasma folate and plasma cobalamin decrease markedly during pregnancy $[28,29]$ suggesting that deficiency of these vitamins may play a yet unidentified role. Women from the Mediterranean, Middle and Far East and Africa may have haemoglobinopathies, which can cause prepartum anaemia. In addition, these women are more prone to present with vitamin deficiencies. In Denmark, these women are screened for haemoglobinopathy in the antenatal health care system.

IDA is by definition an anaemia, which responds to treatment with iron. There exist marked differences between haemoglobin levels in iron-supplemented and nonsupplemented pregnant women $[11,30]$. It is hardly the intention of nature that women shall be iron deficient while being pregnant and we have therefore defined the haemoglobin concentrations found in women without iron deficiency as "optimum" normal values. The haemodilution [22] induces physiological fluctuations in haemoglobin during pregnancy $[11,31,32]$. In iron-supplemented women, haemoglobin concentrations display a steady fall from late first trimester due to haemodilution, reaching a nadir at $\sim 25$ weeks gestation. Subsequently, haemoglobin rises during the remaining period of pregnancy to reach peak levels shortly before delivery [11, 33-38]. This rise prior to delivery is elicited by a combination of an increase in the haemoglobin mass and a decrease in haemodilution. The fluctuations in haemoglobin are different in placebotreated women, where levels continue to fall until $~ 32$ weeks gestation, probably due to iron-deficient erythropoiesis, and thereafter remain quite stable apart from a minor increase shortly before delivery, probably caused by the decrease in haemodilution [11,33-38]. As the degree of haemodilution displays considerable inter-individual variation, "normal" haemoglobin concentrations show similar variation and makes it somewhat complicated to establish reliable cutoff limits for anaemia.

Scandinavian studies $[11,31,32]$ on healthy pregnant Caucasian women without iron deficiency, and living at sea level, have shown that the fifth percentile for blood haemoglobin was $111 \mathrm{~g} / \mathrm{L}$ in the first trimester and $109 \mathrm{~g} / \mathrm{L}$ in the first, $106 \mathrm{~g} / \mathrm{L}$ in the second and $103 \mathrm{~g} / \mathrm{L}$ in the last third of the second trimester and $105 \mathrm{~g} / \mathrm{L}$ in the first two thirds and $110 \mathrm{~g} / \mathrm{L}$ in the last third of the third trimester. Virtually none of the iron-replete women had values $<100 \mathrm{~g} / \mathrm{L}[11,36,38]$. A Danish study [32] on iron-supplemented healthy pregnant women assessed "normal range" using the $95 \%$ reference intervals and found reference values for haemoglobin of 105, 103 and $108 \mathrm{~g} / \mathrm{L}$ at 18, 32 and 39 weeks gestation, respectively.

In order to make these values applicable in the clinical situation, we have simplified the cutoff values for anaemia to: haemoglobin $<110 \mathrm{~g} / \mathrm{L}(<6.8 \mathrm{mmol} / \mathrm{L})$ in the first and third trimester and $<105 \mathrm{~g} / \mathrm{L}(<6.5 \mathrm{mmol} / \mathrm{L})$ in the second trimester. This definition of prepartum anaemia is close to the cutoff value of $110 \mathrm{~g} / \mathrm{L}$ as proposed by the World Health Organisation (WHO) during the entire gestation period [10]. The relationship between haemoglobin $(\mathrm{Hb})$ in grammes per litre and millimoles per litre is expressed in the following equations: $\mathrm{Hb} \mathrm{g} / \mathrm{L} \times 0.062054=\mathrm{Hb} \mathrm{mmol} / \mathrm{L}$; $\mathrm{Hb} \mathrm{mmol} / \mathrm{L} \times 16.115=\mathrm{Hb} \mathrm{g} / \mathrm{L}$.

\section{How frequent is prepartum anaemia?}

There is a lack of systematic, epidemiological studies on the frequency of prepartum anaemia. In Denmark, the National Board of Health does not recommend routine check of haemoglobin in pregnancy. However, at the discretion of their general physician, many women have their haemoglobin measured at their first antenatal visit at 12-14 weeks gestation together with obligatory screening tests for hepatitis virus infection, human immunodeficiency virus infection, etc. During the remaining period of pregnancy, haemoglobin is checked only if the medical history or the clinical examination of the midwife at the antenatal care clinic suggests that the woman may have anaemia. 
It is obvious that the frequency of prepartum IDA is dependent on the woman's iron status prior to pregnancy. During pregnancy, dietary and supplemental iron intake, iron bioavailability, impaired iron absorption due to gastrointestinal diseases and unphysiological blood losses, e.g. uterine haemorrhage, may all contribute to IDA.

The guidelines concerning iron prophylaxis towards IDA during pregnancy vary from country to country (see below) and the frequency of prepartum anaemia would therefore be expected to show similar variations. Despite recommendations on iron prophylaxis, prepartum anaemia is still a major antenatal problem. According to WHO [10], the estimated number of women with prepartum anaemia in Europe is $\sim 2.5$ million.

In order to assess this issue, we have to look at randomised, placebo-controlled studies on iron supplementation, which can give an impression of how frequent anaemia and IDA occurs in pregnant women not taking iron supplements [30]. All studies have reported mean haemoglobin values during pregnancy, which consistently are significantly lower in placebo-treated than in iron-supplemented women [11, 33-41].

In a Danish placebo-controlled study of pregnant women (107 on placebo, 100 on $66 \mathrm{mg}$ elemental ferrous iron per day, from $\sim 14$ weeks gestation) having their haemoglobin measured at regular intervals until delivery (Fig. 2), 5\% of placebo-treated vs $7 \%$ of iron-treated women had anaemia in late second trimester, whereas $22 \%$ vs $2 \%$ had anaemia in late third trimester [11].

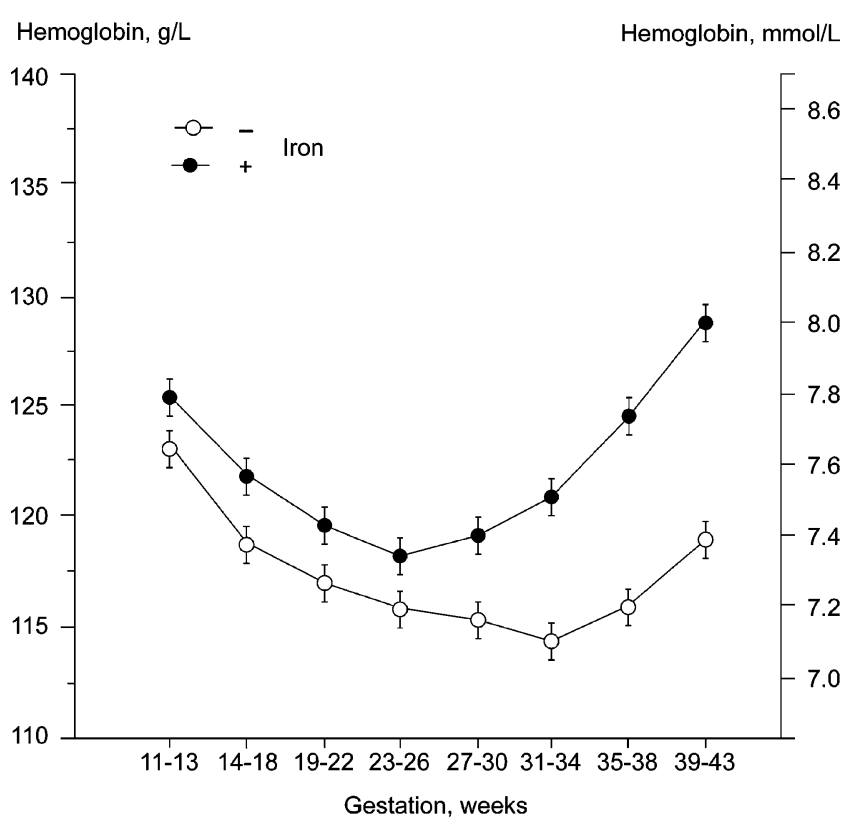

Fig. 2 Blood haemoglobin concentrations (mean \pm SEM) during pregnancy in women taking placebo vs. $66 \mathrm{mg}$ ferrous iron per day from 14 to 18 weeks gestation to delivery [11]
Table 1 gives an overview of placebo-controlled iron prophylaxis studies on pregnant women in the Western societies, which have reported the occurrence of anaemia $[11,34,36-41]$. All studies consistently show that women taking placebo have a markedly higher frequency of anaemia in the second and third trimester compared to women taking iron supplements. In women taking placebo, the frequency of anaemia in the third trimester ranges 14 $52 \%$ and in women taking iron supplements $0-25 \%$, dependent on the doses of iron. In studies incorporating plasma ferritin, the frequency of IDA in placebo-treated women ranges $12-17 \%$ and in iron-supplemented women $0-3 \%[11,12,38,41]$.

Table 2 further illustrates that, in healthy Danish women, the frequency of low haemoglobin levels is significantly higher in placebo-treated than in iron-supplemented women. From all these studies, we can conclude that in the Western societies, prepartum anaemia is still a conspicuous problem in the antenatal health care.

\section{Evaluation of prepartum anaemia}

When a pregnant woman is presenting in the antenatal clinic with anaemia, it is essential to obtain a correct diagnosis in order to institute a specific treatment. The first important step for diagnosing anaemia include a thorough medical history and a medical examination. In the majority of women, i.e. $~ 98 \%$, the anaemia is caused by iron deficiency, which can be confirmed by the examination of appropriate biomarkers of iron status (plasma ferritin, plasma transferrin saturation, serum sTfR). If these tests are indicative of IDA, it should be considered whether the degree of anaemia is consistent with the frequent IDA of pregnancy occurring in women who do not take iron supplements and/or have a low dietary iron intake with a low bioavailability. If IDA occurs in women who take iron supplements, "non-physiologic" causes, e.g. overt or occult bleeding or impaired gastrointestinal iron absorption due to gastric hypochlorhydria or achlorhydria or inflammatory bowel disease, should be considered.

If IDA can be excluded, further evaluation for anaemia should be performed dependent on the history and ethnicity, e.g. plasma folate and plasma cobalamin status, examination for haemolytic anaemia with appropriate tests, examination for haemoglobinopathy with haemoglobin electrophoresis, etc.

\section{Prevention of prepartum vitamin-deficiency-induced anaemia}

It is essential to maintain an optimum vitamin-mineral status during pregnancy and avoid vitamin deficiencies in 
Table 1 Frequency of prepartum anaemia in placebo-controlled studies of iron prophylaxis in Europe and Australia and a Danish dose-response study

\begin{tabular}{|c|c|c|c|c|c|c|c|}
\hline Reference & Treatment & Women $(n)$ & $\begin{array}{l}\text { Ferrous iron } \\
\text { (mg/day) }\end{array}$ & Study period & $\begin{array}{l}\text { Gestation } \\
\text { period }\end{array}$ & $\begin{array}{l}\text { Frequency of } \\
\text { anaemia }(\%)\end{array}$ & $\begin{array}{l}\text { Frequency } \\
\text { of IDA }(\%)\end{array}$ \\
\hline \multirow[t]{2}{*}{ Fleming et al. 1974 [39] } & Placebo & 45 & 60 & 20 weeks to term & 20 weeks to delivery & $20(\mathrm{Hb}<100 \mathrm{~g} / \mathrm{L})$ & \\
\hline & Iron & 57 & & & & $7(\mathrm{Hb}<100 \mathrm{~g} / \mathrm{L})$ & \\
\hline \multirow[t]{2}{*}{ Puolakka et al. 1980 [34] } & Placebo & 16 & 200 & 16 weeks to term & Delivery & 31 & \\
\hline & Iron & 16 & & & & 0 & \\
\hline \multirow[t]{2}{*}{ Foulkes and Goldie 1982 [40] } & Placebo & 250 & 100 & 12 weeks to term & Delivery & $19(\mathrm{Hb}<105 \mathrm{~g} / \mathrm{L})$ & \\
\hline & Iron & 251 & & & & $5(\mathrm{Hb}<105 \mathrm{~g} / \mathrm{L})$ & \\
\hline \multirow[t]{8}{*}{ Romslo et al. 1983 [36] } & Placebo & 23 & 200 & 12 weeks to term & 10-12 weeks & 0 & \\
\hline & & & & & 20-24 weeks & $9^{a}$ & \\
\hline & & & & & 28-32 weeks & 22 & \\
\hline & & & & & Delivery & 30 & \\
\hline & Iron & 22 & & & $10-12$ weeks & 0 & \\
\hline & & & & & 20-24 weeks & $5^{\mathrm{a}}$ & \\
\hline & & & & & 28-32 weeks & 9 & \\
\hline & & & & & Delivery & 5 & \\
\hline \multirow[t]{8}{*}{ Galan et al. 1990 [37] } & Placebo & 84 & 45 & 12 weeks to term & $\sim 12$ weeks & 5 & \\
\hline & & & & & $\sim 20$ weeks & $16^{\mathrm{a}}$ & \\
\hline & & & & & $\sim 35$ weeks & 26 & \\
\hline & & & & & Delivery & 20 & \\
\hline & Iron & 81 & & & $\sim 12$ weeks & 2 & \\
\hline & & & & & $\sim 20$ weeks & $4^{\mathrm{a}}$ & \\
\hline & & & & & $\sim 35$ weeks & 4 & \\
\hline & & & & & Delivery & 3 & \\
\hline \multirow[t]{6}{*}{ Milman et al. 1991 [11] } & Placebo & 108 & 66 & $\sim 14$ weeks to term & 14-18 weeks & 2 & $12^{\mathrm{b}}$ \\
\hline & & & & & 23-26 weeks & 5 & \\
\hline & & & & & Delivery & 14 & $0^{\mathrm{b}}$ \\
\hline & Iron & 99 & & & 14-18 weeks & 0 & \\
\hline & & & & & 23-26 weeks & 7 & \\
\hline & & & & & Delivery & 0 & \\
\hline \multirow[t]{2}{*}{ Eskeland et al. 1997 [38] } & Placebo & 23 & 27 & 20 weeks to term & 20 weeks to delivery & 52 & $17^{\mathrm{c}}$ \\
\hline & Iron & 48 & & & & 25 & $0^{\mathrm{c}}$ \\
\hline \multirow[t]{2}{*}{ Makrides et al. 2003 [41] } & Placebo & 214 & 20 & 20 weeks to term & 28 weeks & 25 & $12^{\mathrm{b}}$ \\
\hline & Iron & 216 & & & & 10 & $3^{b}$ \\
\hline \multirow[t]{6}{*}{ Milman et al. 2005 [12] } & Iron & 105 & 20 & 18 weeks to term & 18 weeks & 2 & $9^{\mathrm{b}}$ \\
\hline & & & & & 32 weeks & 18 & \\
\hline & & & & & Delivery & 3 & \\
\hline & Iron & 322 & $40,60,80$ & & 18 weeks & 1 & $1^{\mathrm{b}}$ \\
\hline & & & & & 32 weeks & 9 & \\
\hline & & & & & Delivery & 3 & \\
\hline
\end{tabular}

Haemoglobin $=\mathrm{Hb}<105 \mathrm{~g} / \mathrm{L}$ in second and $<110 \mathrm{~g} / \mathrm{L}$ in first and third trimester unless otherwise stated

$S F$ Serum ferritin, IDA iron deficiency anaemia

${ }^{\mathrm{a}} \mathrm{Hb}<110 \mathrm{~g} / \mathrm{L}$

${ }^{\mathrm{b}} \mathrm{SF}<12 \mu \mathrm{g} / \mathrm{L}$ and $\mathrm{Hb}<110 \mathrm{~g} / \mathrm{L}$

${ }^{c} \mathrm{SF}<15 \mu \mathrm{g} / \mathrm{L}$ and $\mathrm{Hb}<100 \mathrm{~g} / \mathrm{L}$

order to provide the best nutritional conditions for the pregnant women and for the foetus. With the intension to secure adequate vitamin-mineral supplies, the Danish National Board of Nutrition in 2005 (http://www.altomkost.dk, March 2008) and the Danish Advisory Board of Nutrition in 2007 (http://www.meraadet.dk, March 2008) recommended that pregnant women should take a multivitamin-mineral tablet daily during pregnancy. Ideally, these tablets should be taken in the period prior to conception in order to prevent neural tube defects [42]. Multivitamin-mineral tablets designed for pregnancy contain $0.4 \mathrm{mg}$ folic acid, 1-2 $\mu \mathrm{g}$ vitamin $\mathrm{B}_{12}$ and the various $\mathrm{A}, \mathrm{B}, \mathrm{C}, \mathrm{D}$ and $\mathrm{E}$ vitamins. 
Table 2 Low haemoglobin and iron deficiency anaemia in women taking placebo or iron supplements during pregnancy [11]

\begin{tabular}{|c|c|c|c|c|c|c|c|}
\hline Gestation (weeks) & $14-18$ & $19-22$ & $23-26$ & $27-30$ & $31-34$ & $35-38$ & $39-43$ \\
\hline Trimester & 2 & 2 & 2 & 3 & 3 & 3 & 3 \\
\hline Placebo $(n)$ & 46 & 57 & 56 & 56 & 57 & 57 & 24 \\
\hline Low $\mathrm{Hb}^{\mathrm{a}}(\%)$ & 20 & 14 & 5 & 16 & 19 & 30 & 42 \\
\hline $\operatorname{IDA}^{\mathrm{b}}(\%)$ & 0 & 0 & 0 & 5.4 & 10.5 & 17.5 & 20.8 \\
\hline Ferrous iron, $66 \mathrm{mg}$ /day $(n)$ & 47 & 61 & 62 & 61 & 62 & 59 & 29 \\
\hline Low $\mathrm{Hb}^{\mathrm{a}}(\%)$ & 9 & 5 & 2 & 3 & 5 & 9 & 10 \\
\hline $\operatorname{IDA}^{\mathrm{b}}(\%)$ & 0 & 0 & 0 & 0 & 0 & 0 & 0 \\
\hline $\mathrm{Hb}$ fifth percentile $(\mathrm{g} / \mathrm{L})$ in iron-replete women & 110 & 106 & 103 & 106 & 106 & 110 & 114 \\
\hline
\end{tabular}

${ }^{a}$ Haemoglobin $(\mathrm{Hb})$ below fifth percentile in iron-replete women

${ }^{\mathrm{b}}$ Iron deficiency anaemia: serum ferritin $<12 \mu \mathrm{g} / \mathrm{L}$ and $\mathrm{Hb}$ below fifth percentile in iron-replete women

\section{Guidelines for prevention of prepartum iron deficiency anaemia}

European Union guidelines

The European Commission's report from 1993 [43] concludes that: "The physiologic solution for covering the high iron requirements in pregnancy is to use iron from stores. The problem, however, is that very few women, if any, have iron stores of this magnitude. Therefore, daily iron supplements are recommended in the latter half of pregnancy". To the author's knowledge, these guidelines have not been updated.

\section{Country-specific guidelines}

Some countries, e.g. Germany, have no official guidelines on prepartum iron prophylaxis (http://www.frauenaerzte-imnetz.de, March 2008; http://www.gesundheitpro.de, March 2008). Other countries have quite different guidelines. Some advocate dietary measures, e.g., England and Wales by the National Collaborating Centre for Women's and Children's Health (http://www.rcog.org.uk/resources/Public/ pdf/Antenatal_Care.pdf, March 2008) and Norway by the National Board of Social Welfare and Health (http://www. shdir.no/publikasjoner, March 2008). Several countries advocate oral iron supplementation, e.g. USA by the Centres for Disease Control and Prevention [44] and the International Food Information Council Foundation (http://www.ific.org), Denmark by the National Board of Health (http://www. altomkost.dk, March 2008) and the Advisory Board of Nutrition (http://www.meraadet.dk, March 2008) and Sweden by the National Board of Nutrition (http://www.slv.se, March 2008).

The health authorities in the USA recommend general iron prophylaxis with $30 \mathrm{mg}$ ferrous iron per day at bedtime from the first visit at the maternity clinic to delivery (http:// www.ific.org) [44]. In Denmark, the National Board of Health and the National Board of Nutrition recommend general iron prophylaxis of 50-70 $\mathrm{mg}$ of ferrous iron per day at bedtime from 20 weeks gestation to delivery (http:// www.altomkost.dk, March 2008) whereas the Advisory Board of Nutrition advocates individual iron prophylaxis from early pregnancy to delivery using ferrous iron in doses adjusted according to iron status (http://www.meraadet.dk, March 2008).

\section{Prophylaxis of prepartum iron deficiency anaemia}

\section{Dietary measures}

In some countries (http://www.rcog.org.uk/resources/Public/ pdf/Antenatal_Care.pdf, March 2008; http://www.shdir.no/ publikasjoner, March 2008), guidelines to pregnant women are focussed on changing dietary habits towards foods with high iron content and high iron bioavailability. However, this approach is purely theoretical and has not, to the author's knowledge, been substantiated by any controlled study.

Overall, women do not change their dietary habits during pregnancy [45], so we can estimate dietary intakes from nutrition surveys in non-pregnant women. Danish menstruating non-pregnant women have a mean dietary iron intake of $\sim 9 \mathrm{mg}$ /day [46], which means that more than $90 \%$ of the women have an intake below the recommended daily allowance of $\sim 18 \mathrm{mg} /$ day [47].

A Scandinavian survey reported that the energy intake and composition of the diet was similar prior to pregnancy and at 17 and 33 weeks gestation [45]. Mean energy intake was $\sim 9 \mathrm{~mJ} /$ day [45], i.e. the same as in non-pregnant women [46]; $96 \%$ of the women had a dietary iron intake below $18 \mathrm{mg} /$ day. Thus, the majority of fertile women in the Western countries have a dietary iron intake, which cannot fulfil the demands in the second and third trimester. The inadequate iron intake is predominantly caused by a low energy intake, which is a consequence of the prevailing sedentary lifestyle in the Western societies. 
Even under favourable conditions, at the most, $30 \%$ of dietary iron can be absorbed, corresponding to $3 \mathrm{mg}$ iron per day from a dietary iron intake of $9 \mathrm{mg} /$ day, i.e. considerably less than the daily iron requirements during pregnancy. In the average Scandinavian diet, the bioavailability of iron is $\sim 18 \%$. Estimates from the USA suggest that the recommended dietary allowance of iron should be $\sim 27 \mathrm{mg} /$ day with a bioavailability of at least $25 \%$ in order to fulfil the needs during pregnancy (http://www.ific.org). However, in order to obtain an iron intake of this magnitude, the women should make unrealistic changes in their diet. As we realise that dietary iron cannot fulfil iron requirements during pregnancy in the majority of women, the Nordic Nutrition Recommendations have refrained from giving recommendations for dietary iron intake [47]. Instead, they advocate oral iron supplements to women with iron stores of $<500 \mathrm{mg}$ (corresponding to plasma ferritin of $<70 \mu \mathrm{g} / \mathrm{L}$ ).

\section{Oral iron prophylaxis}

Placebo-controlled studies have consistently shown that pregnant women using iron supplements $[11,30,33-$ 41] have significantly higher iron status compared to women taking placebo. Consequently, women taking iron have a lower frequency of anaemia than women taking placebo as shown in Tables 1 and 2. These observations provide strong evidence that many pregnant women not taking iron supplements have iron-deficient erythropoiesis.

Previously, high doses of ferrous iron in the range 100 $200 \mathrm{mg} /$ day were advocated to pregnant women [33, 34, $36,40,48]$. A dose of $100 \mathrm{mg}$ ferrous iron per day induces a maximum rise in haemoglobin [33] and $200 \mathrm{mg}$ ferrous iron per day increases both plasma ferritin and haemoglobin at delivery to the same levels as in non-pregnant women $[33,48]$. However, novel research have emphasised the potential deleterious effects of iron on the human body [30] and therefore encouraged studies using smaller doses of iron $[11,35,37]$ and studies trying to define the smallest effective dose [12, 38, 41, 49].

European studies have shown that a supplement of 45 $66 \mathrm{mg}$ ferrous iron per day taken between meals from 12 to 20 weeks gestation to delivery is adequate to prevent IDA in healthy pregnant women $[11,35,37,39]$. Even smaller doses of 20-27 mg ferrous iron per day appear to have a favourable influence on iron status $[12,30,38,41]$. In a Danish dose-response study [12], $40 \mathrm{mg}$ ferrous iron per day taken between meals was adequate to prevent IDA, but $20 \mathrm{mg}$ iron per day was significantly inferior to $40 \mathrm{mg}$ /day as regards the prevention of iron deficiency. There was no benefit in giving higher doses of iron, i.e. 60 or $80 \mathrm{mg}$. The overall conclusion of these studies are firstly that $30-40 \mathrm{mg}$ ferrous iron per day appears adequate to prevent IDA and secondly that low-dose iron supplements in the range 20 $27 \mathrm{mg} /$ day are better than no supplements at all.

It would be convenient for the woman if iron supplements could be taken as combined multivitamin-mineral preparations. Nutritional supplements in Denmark designed for pregnant women contain $15-27 \mathrm{mg}$ ferrous iron. However, a daily dose of $18 \mathrm{mg}$ ferrous iron contained in a multivitamin-mineral tablet taken from 16 weeks gestation is inadequate to prevent iron deficiency in $72 \%$ of the women [49]. This is consistent with the fact that, in epidemiological studies, daily use of multivitamin-mineral tablets containing 14-18 mg ferrous iron has no impact on iron status in women [50].

To the author's knowledge, the absorption of iron from multivitamin-mineral supplements has not been evaluated. Probably, there is a low absorption of iron for several reasons. Firstly, it is recommended that multivitamin-mineral tablets should be taken with meals, which clearly will reduce the bioavailability of iron. Dietary components, e.g. calcium, polyphenols and phytates, inhibit the absorption of ferrous iron supplements $\sim 40 \%$, especially at low doses of iron $[51,52]$. Therefore, iron supplements should be taken between meals, e.g. at bedtime, in order to ensure maximum absorption [12]. Secondly, iron in multivitamin-mineral supplements is administered together with other essential divalent metal ions (zinc, copper, manganese, etc.), which compete with each other about the absorptive capacity in the gastrointestinal tract $[30,53,54]$. The consequence of these considerations should be to withdraw iron from multivitamin-mineral tablets designed for pregnancy and administer iron in separate tablets.

As a consequence of these considerations, as general iron prophylaxis to pregnant women, we recommend lowdose ferrous iron supplement of 30-40 mg/day at bedtime or between meals from early pregnancy or from the first antenatal care visit to delivery $[30,44]$.

Due to the potential drawbacks of iron supplements, individual iron prophylaxis based on assessment of iron status (plasma ferritin) either prior to or in early pregnancy appears to be a more physiological approach than general iron prophylaxis. Our recommendations for individual iron prophylaxis have been stated previously [30]. Women with plasma ferritin of $>70 \mu \mathrm{g} / \mathrm{L}$ do not need iron supplements; those with ferritin of 30-70 $\mu \mathrm{g} / \mathrm{L}$ should take $30-40 \mathrm{mg}$ ferrous iron per day and those with ferritin of $<30 \mu \mathrm{g} / \mathrm{L}$ should take $80-100 \mathrm{mg}$ ferrous iron per day [30].

In conclusion, oral iron supplementation, general or individual, in pregnant women starting in early pregnancy appears to very efficient in the prevention of anaemia. 


\section{Treatment of prepartum iron deficiency anaemia}

IDA should be treated by replenishing body iron deficits either by oral or intravenous administration of iron. In this context, intramuscular administration of iron is hardly applicable in the Western societies due to the small iron dose per injection and the painful local reactions. Two recent guidelines on prepartum anaemia have been launched in 2007, by the Schweizerische Gesellschaft für Gynäkologie und Geburtshilfe [55] and by the Network for Advancement of Transfusion Alternatives (Table 3) [56].

\section{Oral iron}

Iron absorption is regulated according to body iron reserves and the intensity of erythropoiesis. It is well documented that exhausted body iron reserves in otherwise healthy women will increase the intestinal iron absorption [52]. Furthermore, the increased erythropoietin-induced erythropoiesis during the second and third trimester [57] stimulates iron absorption. This combined stimulation of iron absorption has been confirmed in studies showing that iron absorption increases with increasing length of gestation, being most pronounced after 20 weeks gestation [33, 58, 59]. However, the marked increase in iron absorption is caused by iron deficiency, i.e. pregnant women with replete iron stores have an absorption, which is almost similar to the absorption in nonpregnant iron-replete women $[33,60]$.

This high iron absorption capacity is quite favourable for treatment of IDA with oral iron in pregnant women. During treatment of IDA, absorption is highest in the first 2 weeks and subsequently declines [61]. There is consensus that oral iron therapy should be the first therapeutic option in the first and second trimester $[55,56]$. Women having slight to moderate IDA with haemoglobin of 90-105 g/L should initially be treated with ferrous iron. The recommended doses are traditionally quite high, i.e. 100-200 mg elemental iron per day, being based on old studies performed in anaemic men [61]. High-dose iron therapy should preferably be administered as sustained release iron preparations in order to optimise absorption and reduce gastrointestinal side effects [62]. However, a recent study of anaemic pregnant women has questioned the use of highdose oral iron therapy and presented evidence for the efficiency of ferrous iron in doses of $20-80 \mathrm{mg} /$ day, taken between meals [63]. The effect on iron status increased with iron dose $(20 \rightarrow 40 \rightarrow 80 \mathrm{mg} /$ day $)$ and was highest with the 80-mg dose [63]. As a consequence of this study, the recommended standard dose for treatment of IDA should hardly exceed $100 \mathrm{mg}$ ferrous iron per day taken between meals. Following oral iron treatment for 2 weeks, the therapeutic response should be checked by assessment of haemoglobin. If haemoglobin has increased $\geq 10 \mathrm{~g} / \mathrm{L}$, oral iron therapy should continue during the remaining period of gestation with subsequent check of haemoglobin and plasma ferritin. When haemoglobin has reached a level of $>105 \mathrm{~g} / \mathrm{L}$, the iron dose may be reduced to $60-80 \mathrm{mg} /$ day as maintenance therapy.

A failing haemoglobin response to treatment could be the consequence of non-compliance due to psychological mechanisms, non-compliance due to gastrointestinal side effects, impaired gastrointestinal iron absorption due to achlorhydria or inflammatory bowel disease or nonrecognised ongoing bleeding with iron losses.

\section{Intravenous iron}

Treatment with intravenous iron is clearly superior to oral iron with respect to a faster increase in haemoglobin and faster replenishment of body iron stores [64-66]. Intravenous iron reduces the need for blood transfusions and constitutes an alternative to transfusion in profound IDA [67]. Intravenous iron preparations comprise among others iron sucrose (Venofer ${ }^{\circledR}$, Vifor, St. Gallen, Switzerland) [68], low molecular weight iron dextran $\left(\right.$ Cosmofer ${ }^{\circledR}$, Pharmacosmos, Holbæk, Denmark) [69] and the recently introduced iron carboxymaltose (Ferinject ${ }^{\circledR}$, Vifor, St. Gallen, Switzerland) [70]. Provided the Summary of Product Characteristics (SPC) are observed, the frequency of adverse events is below $0.5 \%$ [64, 65, 68-70]. Infusion of iron should be

Table 3 Guidelines for treatment of prepartum iron deficiency anaemia

Schweizerische Gesellschaft für Gynäkologie und Geburtshilfe [55]

Network for Advancement of Transfusion Alternatives [56]

Slight to moderate IDA=haemoglobin $90-105 \mathrm{~g} / \mathrm{L}$

1. Give oral iron in 1 st and 2 nd trimester

1. Give oral iron $160-200 \mathrm{mg} /$ day

2. If haemoglobin increases to $<10 \mathrm{~g} / \mathrm{L}$ in 2 weeks (non-responders), consider intravenous iron in second and third trimester

2. If haemoglobin increases $<5 \mathrm{~g} / \mathrm{L}$ in 2 weeks (non-responders), consider intravenous iron at $>14$ weeks gestation

Severe IDA=haemoglobin $<90 \mathrm{~g} / \mathrm{L}$

1. Give intravenous iron in separate doses of $200 \mathrm{mg}$ until haemoglobin is $>105 \mathrm{~g} / \mathrm{L}$

2. Consider maintenance therapy with oral iron 
given on an outpatient basis in a setting where equipment for cardiopulmonary resuscitation is available. Infusion should be given in peripheral veins and care should be taken to avoid chemical phlebitis at the infusion site. In severe IDA being resistant to oral iron, intravenous iron treatment can be combined with the administration of recombinant human erythropoietin of $\sim 20,000 \mathrm{U}$ subcutaneously in order to further stimulate the erythropoiesis [71].

Intravenous iron is considered safe in the second and third trimester $[55,56]$. There is limited experience in the fist trimester concerning the potential teratogenic and/or toxic effects on the foetus. Consequently, if parenteral iron treatment is mandatory in the first trimester, the choice stands between intravenous iron and blood transfusions, the latter method carrying the well-known risks.

Treatment with intravenous iron should be considered at: (1) as second option if oral iron fails to increase haemoglobin within 2 weeks; (2) as first option at profound IDA, i.e. haemoglobin of $<90 \mathrm{~g} / \mathrm{L}$ in any trimester beyond 14 weeks gestation; (3) as first option at IDA in the third trimester.

Profound IDA has serious consequences for both the pregnant women and the foetus [4-8] and requires prompt intervention. In the first trimester, a combination of highdose oral and low-dose intravenous iron could be the choice, otherwise blood transfusion should be considered. In the second and third trimester, intravenous iron should be the preferred treatment [56]. In the third trimester, there is too short time for oral iron therapy to be effective and it is imperative to alleviate IDA and replenish iron reserves prior to delivery in order to prevent peripartum anaemia and avoid blood transfusions. This is especially important in women who for religious or other reasons oppose blood transfusions.

The dose of intravenous iron should be adequate to obtain a haemoglobin level of $>105 \mathrm{~g} / \mathrm{L}$. In the majority of women, a total dose of 600-1,200 $\mathrm{mg}$ intravenous iron is adequate.

When a haemoglobin of $>105 \mathrm{~g} / \mathrm{L}$ has been reached, the women can subsequently switch to maintenance treatment with oral ferrous iron of $80-100 \mathrm{mg}$ /day taken between meals, provided they have normal gastrointestinal iron absorption.

Iron sucrose should be given in repetitive doses of maximum of $200 \mathrm{mg}$ iron pro dosis dissolved in minimum $100 \mathrm{ml}$ isotonic saline and infused over at least $30 \mathrm{~min}[55$, 68]. Separate doses should be administered with $~ 3$-day interval. Low molecular weight iron dextran is less prone to produce hypotension $(<0.1 \%)$ [69] than iron sucrose $(<1 \%)$ [68], while the frequency of serious adverse events appears to be the same.

In non-pregnant patients, iron dextran can be administered as "total dose infusion" where up to $20 \mathrm{mg}$ iron per kilogram body weight is given in a single infusion $[69,72]$. However, there is limited experience concerning its use in pregnancy. According to the SPC [69], prior to the first administration, a test dose of $25 \mathrm{mg}$ iron dissolved in $100 \mathrm{~mL}$ isotonic saline should be infused over $15 \mathrm{~min}$. If no adverse reaction has occurred $60 \mathrm{~min}$ after the test, 500-1,000 mg iron should be dissolved in $500 \mathrm{~mL}$ isotonic saline and infused over $4 \mathrm{~h}$. At subsequent infusions, $25 \mathrm{mg}$ iron should be infused over 15 min and, if no adverse reactions are seen, the remainder of the infusion can be administered.

Iron carboxymaltose has recently been introduced on the European market and has proved effective in the treatment of postpartum anaemia [73]. According to the SPC [70], up to $1,000 \mathrm{mg}$ iron dissolved in $250 \mathrm{~mL}$ isotonic saline can be given as a single infusion over $15 \mathrm{~min}$. However, due to the limited experience with this novel iron compound, its use in pregnant women should await further controlled clinical trials.

The total dose infusion concept, which is convenient for the patient and save resources in the health care system, can probably also be applied to pregnant women beyond the first trimester, but the experience is until now scarce and further controlled studies are needed. Intravenous iron treatment appears effective in correcting both the anaemia and quality-of-life deficits and shows promising aspects in the future management of prepartum IDA.

\section{Conclusion}

Iron deficiency anaemia is the most frequent form of anaemia in pregnant women. The diagnosis of IDA relies on blood haemoglobin and plasma ferritin. Among fertile, non-pregnant women, $\sim 40 \%$ have an unfavourable iron status with respect to upcoming pregnancy. The prevalence of prepartum anaemia in the third trimester ranges $14-52 \%$ in women taking placebo and $0-25 \%$ in women taking iron supplements. The frequency of IDA in placebo-treated women ranges $12-17 \%$ and in iron-supplemented women 0-3\%. Dietary measures are inadequate to reduce the frequency of prepartum IDA, which, however, is prevented by oral iron supplements $30-40 \mathrm{mg}$ ferrous iron per day taken at bedtime or between meals from early pregnancy to delivery. Treatment of IDA should aim at replenishing body iron deficits by oral and/or intravenous administration of iron. In women with slight to moderate IDA treatment with oral ferrous iron of $\sim 100 \mathrm{mg} /$ day between meals is the initial therapeutic option in the first and second trimester. Treatment with intravenous iron is superior to oral iron concerning the haematological response and is considered safe in the second and third trimester.

Intravenous iron should be considered if oral iron fails to increase haemoglobin within 2 weeks, at profound IDA with haemoglobin of $<90 \mathrm{~g} / \mathrm{L}$ in any trimester beyond 14 weeks gestation and at IDA in the third trimester. Severe IDA requires prompt intervention, especially in women who for various reasons oppose blood transfusions. 
Acknowledgement The author is indebted to Chief Physician Jens Hertz, Department of Obstetrics, Gentofte Hospital, University of Copenhagen, Hellerup, Denmark for constructive revision of the manuscript.

Open Access This article is distributed under the terms of the Creative Commons Attribution Noncommercial License which permits any noncommercial use, distribution, and reproduction in any medium, provided the original author(s) and source are credited.

\section{References}

1. Bruner A, Joffe A et al (1996) Randomised study of cognitive effects of iron supplementation in non-anemic iron-deficient adolescent girls. Lancet 348:992-996 doi:10.1016/S0140-6736 (96)02341-0

2. Rowland TW, Deisroth MB, Green GM, Kelleher JF (1988) The effect of iron therapy on the exercise capacity of non-anemic irondeficient adolescent runners. Am J Dis Childhood 142:165-169

3. Beard JL, Hendricks MK, Perez EM et al (2005) Maternal iron deficiency anemia affects postpartum emotions and cognition. J Nutr 135:267-272

4. Sagen N, Nielsen ST, Kim HC, Bjergsø P, Koller O (1984) Maternal hemoglobin concentration is closely related to birth weight in normal pregnancies. Acta Obstet Gynecol Scand 63:245-248

5. Murphy JF, Newcombe RG, O'Riordan J, Coles EC, Pearson JF (1986) Relation of haemoglobin levels in the first and second trimesters to outcome of pregnancy. Lancet 1:992-994 doi:10.1016/S0140-6736(86)91269-9

6. Steer P, Alam MA, Wadsworth J, Welch A (1995) Relation between maternal haemoglobin concentration and birth weight in different ethnic groups. Br Med J 310:489-491

7. Scanlon KS, Yip R, Schieve LA, Cogswell ME (2000) High and low hemoglobin levels during pregnancy: differential risks for preterm birth and small for gestational age. Obstet Gynecol 96:741-748 doi:10.1016/S0029-7844(00)00982-0

8. Ren A, Wang J, Ye RW, Li S, Liu JM, Li Z (2007) Low firsttrimester hemoglobin and low birth weight, preterm birth and small for gestational age newborns. Int J Gynaecol Obstet 98:124128 doi:10.1016/j.ijgo.2007.05.011

9. Milman N (2006) Iron and pregnancy - a delicate balance. Ann Hematol 85:559-565 doi:10.1007/s00277-006-0108-2

10. World Health Organization (2001) Iron deficiency anaemia. Assessment, prevention and control. WHO/NHD/01.3.

11. Milman N, Agger OA, Nielsen OJ (1991) Iron supplementation during pregnancy. Effect on iron status markers, serum erythropoietin and human placental lactogen. A placebo controlled study in 207 Danish women. Dan Med Bull 38:471-476

12. Milman N, Bergholt T, Eriksen L, Byg K-E, Graudal N, Pedersen P, Hertz J (2005) Iron prophylaxis during pregnancy - how much iron is needed? A randomised, controlled study of 20 to $80 \mathrm{mg}$ ferrous iron daily to pregnant women. Acta Obstet Gynecol Scand 84:238-247 doi:10.1111/j.0001-6349.2005.00610.x

13. Walters GO, Miller FM, Worwood M (1973) Serum ferritin concentration and iron stores in normal subjects. J Clin Pathol 26:770-772 doi:10.1136/jcp.26.10.770

14. Milman N (1996) Serum ferritin in Danes: studies of iron status from infancy to old age, during blood donation and pregnancy. Int J Hematol 63:103-135 doi:10.1016/0925-5710(95)00426-2

15. Milman N, Strandberg NS, Visfeldt J (1983) Serum ferritin in healthy Danes: relation to marrow haemosiderin iron stores. Dan Med Bull 30:115-120
16. Worwood M (1994) Laboratory determination of iron status. In: Brock JH, Halliday JW, Pippard MJ, Powell LW (eds) Iron metabolism in health and disease. Saunders, London, pp 449-476

17. Baynes RD (1994) Iron deficiency. In: Brock JH, Halliday JW, Pippard MJ, Powell LW (eds) Iron metabolism in health and disease. Saunders, London, pp 204-207

18. Carriage MT, Skikne S, Finley B, Cutler B, Cook JD (1991) Serum transferrin receptor for the detection of iron deficiency. Am J Clin Nutr 54:107-181

19. Akesson A, Bjellerup P, Berglund M, Bremme K, Vahter M (1998) Serum transferrin receptor: a specific marker of iron deficiency in pregnancy. Am J Clin Nutr 68:1241-1246

20. Cook JD, Flowers CH, Skikne BS (2003) The quantitative assessment of body iron. Blood 101:3359-3364 doi:10.1182/ blood-2002-10-3071

21. Milman N, Byg K-E, Bergholt T, Eriksen L, Hvas A-M (2006) Body iron and individual iron prophylaxis in pregnancy - should the iron dose be adjusted according to serum ferritin? Ann Hematol 85:567-573 doi:10.1007/s00277-006-0141-1

22. Koller O (1982) The clinical significance of hemodilution during pregnancy. Obstet Gynecol Surv 37:649-652 doi:10.1097/ 00006254-198211000-00001

23. Milman N, Byg K-E, Ovesen L (2000) Iron status in Danes updated 1994. II. Prevalence of iron deficiency and iron overload on 1319 women aged 40-70 years. Influence of blood donation, alcohol intake, and iron supplementation. Ann Hematol 79:612621 doi: $10.1007 / \mathrm{s} 002770000209$

24. Bothwell TH (2000) Iron requirements in pregnancy and strategies to meet them. Am J Clin Nutr 72:257S-264S

25. Milman N, Clausen J, Byg K-E (1998) Iron status in 268 Danish women aged 18-30 years. Influence of menstruation, method of contraception, and iron supplementation. Ann Hematol 76:13-19 doi: $10.1007 / \mathrm{s} 002770050405$

26. Milman N, Graudal N, Galløe A, Agger AO (1996) Serum ferritin and selective iron prophylaxis in pregnancy? J Intern Med 240:47-50

27. Nybo M, Friis-Hansen L, Felding P, Milman N (2007) Higher prevalence of anaemia among pregnant immigrant women compared to pregnant ethnic Danish women. Ann Hematol 86:647-651 doi:10.1007/s00277-007-0305-7

28. Milman N, Byg K-E, Hvas A-M, Bergholt T, Eriksen L (2006) Erythrocyte folate, plasma folate and plasma homocysteine during normal pregnancy and postpartum: a longitudinal study comprising 404 Danish women. Eur J Haematol 76:200-205 doi:10.1111/ j.1600-0609.2005.00606.x

29. Milman N, Byg K-E, Bergholt T, Eriksen L, Hvas A-M (2006) Cobalamin status during normal pregnancy and postpartum. A longitudinal study comprising 406 Danish women. Eur J Haematol 76:521-525 doi:10.1111/j.0902-4441.2006.t01-1-EJH2550.x

30. Milman N (2006) Iron prophylaxis in pregnancy - general or individual and in which dose? Ann Hematol 85:821-828 doi:10.1007/s00277-006-0145-x

31. Milman N, Byg K-E, Graudal N, Agger AO (2000) Reference values for hemoglobin and erythrocyte indices during normal pregnancy in 206 women with and without iron supplementation. Acta Obstet Gynecol Scand 78:89-98 doi:10.1034/j.16000412.2000.079002089.x

32. Milman N, Bergholdt T, Byg K-E, Eriksen L, Hvas A-M (2007) Reference intervals for haematological variables during normal pregnancy and postpartum in 433 healthy Danish women. Eur J Haematol 79:39-46 doi:10.1111/j.1600-0609.2007.00873.x

33. Svanberg B (1975) Absorption of iron in pregnancy. Acta Obstet Gynecol Scand Suppl 48:87-108

34. Puolakka J, Jänne O, Pakarinen A, Järvinen PA, Vihko R (1980) Serum ferritin as a measure of iron stores during and after normal pregnancy with and without iron supplements. Acta Obstet Gynecol Scand suppl. 95:43-51 
35. Taylor DJ, Mallen C, McDougall N, Lind T (1982) Effect of iron supplementation on serum ferritin levels during and after pregnancy. Br J Obstet Gynaecol 89:1011-1017

36. Romslo I, Haram K, Sagen N, Augensen K (1983) Iron requirement in normal pregnancy as assessed by serum ferritin, serum transferrin saturation, and erythrocyte protoporphyrin determination. Br J Obstet Gynaecol 90:101-107

37. Galan P, Wainer R, De Benaze C, Hercberg S (1990) Prevention de l'anemie ferriprive au cours de la grossesse: effet de la supplementation precoce en fer. In: Hercberg S, Galan P, Dupin H (eds) Recent knowledge on iron and folate deficiencies in the world. vol. 197. Colloque INSERM, Paris, p 615

38. Eskeland E, Malterud K, Ulvik RJ, Hunskaar S (1997) Iron supplementation in pregnancy: is less enough? Acta Obstet Gynecol Scand 76:822-828 doi:10.3109/00016349709024359

39. Fleming AF, Martin JD, Hahnel R, Westlake AJ (1974) Effects of iron and folic acid antenatal supplements on maternal haematology and fetal wellbeing. Med J Austr 2:429-436

40. Foulkes J, Goldie DJ (1982) The use of ferritin to assess the need for iron supplements in pregnancy. J Obstet Gynaecol 3:11-16 doi: $10.3109 / 01443618209083074$

41. Makrides M, Crowther CA, Gibson RA, Gibson RS, Skeaff CM (2003) Efficacy and tolerability of low-dose iron supplements during pregnancy: a randomised controlled trial. Am J Clin Nutr $78: 145-153$

42. van der Put NM, van Straaten HW, Trijbels FJ, Blom HJ (2001) Folate, homocysteine and neural tube defects: an overview. Exp Biol Med (Maywood) 226:243-270

43. Commission of the European Communities (1993) Nutrient and energy intakes for the European Community. Reports of the Scientific Committee for Food. Directorate General Industry 31st series $180-1$

44. Anonymous (1998) Recommendations to prevent and control iron deficiency in the United States. Centers for Disease Control and Prevention. MMWR Recomm Rep 47:1-29

45. Trygg K, Lund-Larsen K, Sandstad B, Hoffman HJ, Jacobsen G, Bakketeig LS (1995) Do pregnant smokers eat differently from pregnant non-smokers? Pediatric Perinatal Epidemiology 9:307-319

46. Lyhne N, Christensen T, Groth MV et al (2005) Dietary habits in Denmark 2000-2002. Main results. Publication no. 11. National Food Agency of Denmark, Copenhagen

47. Nordic Council of Ministers (2004) Nordic nutrition recommendations 2004. Nordic Council of Ministers, Copenhagen

48. Milman N, Ibsen KK, Christensen JM (1987) Serum ferritin and iron status in mothers and newborn infants. Acta Obstet Gynecol Scand 66:205-211

49. Thomsen JK, Prien-Larsen JC, Devantier A, Fogh-Andersen N (1993) Low dose iron supplementation does not cover the need for iron during pregnancy. Acta Obstet Gynecol Scand 72:93-98

50. Milman N, Kirchhoff M (1992) Iron stores in 1359, 30- to 60year-old Danish women: evaluation by serum ferritin and hemoglobin. Ann Hematol 64:22-27

51. Brise H (1962) Influence of meals on iron absorption in oral iron therapy. Acta Med Scand 171(suppl. 376):39-45

52. Skikne B, Baynes RD (1994) Iron absorption.. In: Brock JH, Halliday JW, Pippard MJ, Powell LW (eds) Iron metabolism in health and disease. Saunders, London, pp 151-187

53. Rossander-Hultén L, Brune M, Sandström B, Lönnerdal B, Hallberg L (1991) Competitive inhibition of iron absorption by manganese and zinc in humans. Am J Clin Nutr 54:152-156

54. O'Brien KO, Zavaleta N, Caulfield LE, Wen J, Abrams SA (2000) Prenatal iron supplements impair zinc absorption in pregnant Peruvian women. J Nutr 130:2251-2255

55. Breymann C, Honegger C, Holzgreve W, Surbek D (2007) Diagnostik und Therapie der Anämie in der Schwangerschaft und postpartal. Schweizerische Gesellschaft für Gynäkologie und Geburtshilfe. Expertenbrief 2007 no. 22.

56. Beris P, Maniatis A, on behalf of the NATA working group on intravenous iron therapy (2007) Guidelines on intravenous iron supplementation in surgery and obstetrics/gynecology. TATM transfus Altern Transfus Med 9(Suppl 1):29

57. Milman N, Graudal N, Nielsen OJ, Agger AO (1997) Serum erythropoietin during normal pregnancy: relationship to hemoglobin and iron status markers and impact of iron supplementation in a longitudinal, placebo-controlled study on 118 women. Int J Hematol 66:159-168

58. Heinrich HC, Bartels H, Heinisch B, Hausmann K, Kuse R, Humke W, Mauss HJ (1968) Intestinale 59Fe-Resorption und prälatenter Eisenmangel während der Gravidität des Menschen. Klin Wschr 46:199-202

59. Barrett FR, Whittaker PG, Williams JG, Lind T (1994) Absorption of non-haem iron from food during normal pregnancy. Br Med J 309:79-82

60. O'Brien KO, Zavaleta N, Caulfield LE, Yang D-X, Abrams SA (1999) Influence of prenatal iron and zinc supplements on supplemental iron absorption, red blood cell iron incorporation, and iron status in pregnant Peruvian women. Am J Clin Nutr 69:509-515

61. Norrby A (1974) Iron absorption studies in iron deficiency. Scand J Haematol suppl 20:1-125

62. Nielsen JB, Ikkala E, Sölvell L, Björn-Rasmussen E, Ekenved G (1976) Absorption of iron from slow-release and rapidlydisintegrating tablets - a comparative study in normal subjects, blood donors and subjects with iron deficiency anaemia. Scand J Heamatol Suppl 28:89-97

63. Zhou SJ, Gibson RA, Crowther CA, Makrides M (2007) Should we lower the dose of iron when treating anaemia in pregnancy? A randomised dose-response trial. Eur J Clin Nutr published online 10 Oct. doi:10.1038/sj.ejcn.1602926

64. Bashiri A, Burstein E, Sheiner E, Mazor M (2003) Anaemia during pregnancy and treatment with intravenous iron: review of the literature. Eur J Obstet Gynecol Reprod Biol 110:2-7

65. al-Momen AK, al-Meshari A, al-Nuaim L, Saddique A, Abotalib Z, Khashogji $T$ et al (1996) Intravenous iron sucrose complex in the treatment of iron deficiency anemia during pregnancy. Eur J Obstet Gynecol Reprod Biol 69:121-124

66. al-Ragip A, Unlubilgin E, Kandemir O, Yalvac S, Cakir L, Haberal A (2005) Intravenous versus oral iron for treatment of anemia in pregnancy: a randomized trial. Obstet Gynecol 106:1335-1340

67. Hallak M, Sharon A, Duikman R, Auslender R, Abramovici H (1997) Supplementing iron intravenously in pregnancy. A way to avoid blood transfusions. J Reprod Med 42:99-103

68. Danish Medicines Agency (2007) Venofer ${ }^{\circledR}$. Summary of product characteristics.

69. Danish Medicines Agency (2007) CosmoFer ${ }^{\circledR}$. Summary of product characteristics.

70. Danish Medicines Agency (2007) Ferinject ${ }^{\circledR}$. Summary of product characteristics.

71. Breymann C, Visca E, Huch R, Huch A (2001) Efficacy and safety of intravenously administered iron sucrose with and without adjuvant recombinant human erythropoietin for the treatment of resistant iron-deficiency anemia during pregnancy. Am J Obstet Gynecol 184:662-667

72. Auerbach M, Winchester J, Wahab A et al (1998) A randomized trial of three iron dextran infusion methods for anemia in EPOtreated dialysis patients. Am J Kidney Dis 31:81-86

73. Van Wyck DB, Martens MG, Seid MH, Baker JB, Mangione A (2007) Intravenous ferric carboxymaltose compared with oral iron in the treatment of postpartum anemia. A randomised controlled trial. Obstet Gynecol 110:267-278 